\title{
Scoring System in Dermatology: A Review
}

\author{
Dr. Ridhima Lakhani ${ }^{1}$, Dr. Chaitra Prakash ${ }^{2}$, Dr. Siddhi Tiwari ${ }^{3}$,Dr. Saroj \\ Purohit $^{4}$, Dr. Vijay Paliwal ${ }^{5}$, Dr. Deepak K. Mathur ${ }^{6}$, Dr. Puneet Bhargava ${ }^{7}$ \\ 1,2,3,4,5,6,7 Dept. Of Dermatology, SMS Medical College, Jaipur(Raj)
}

Abstract : In dermatology over years many scoring systems have been developed which help develop objectivity in clinical observation of various skin disorders. These scores use criteria which can be easily studied clinically and compared and are easily responsive to routine treatments .

The scoring helps us in grading the severity of a particular disease, guiding therapy, also measuring the response of the treatment. Thus, these scoring systems help us predicting the prognosis of a particular disease .

Keywords: Dermatology, scoring systems, prognosis.

\section{Introduction}

In dermatological practice, methods of evaluating the severity of skin diseases are often crude, subjective and not reproducible, which creates discrepancy in results and inter-individual variations. Hence, to maintain objectivity in observations, scores are used to evaluate the severity of skin diseases. This is particularly important for monitoring the response to therapy and for evaluating the efficacy of new drugs.

Scores helps us in semiobjective assessment of skin diseases. Till better objective parameters are developed, scores will continue to remain the gold standard for assessing the severity of dermatological diseases in clinical research. Thus we have tried to compile the scoring systems used in all the major dermatological diseases.

\section{Methods and materials}

10 year review articles from 2006 to 2016 appearing in various indices like Pubmed, Copernicus, Embase and Google scholar were reviewed for various scoring systems in dermatology. The following scoring systems were obtained ${ }^{1}$ :

a. Atopic dermatitis: SCORAD \& SASSAD

b. Poriasis : PASI, SAPSI, SPI, E-PAP.

c. Nail psoriais : NAPSI

d. TEN : SCORTEN

e. Vitiligo : VIDA \& VASI

f. Scleroderma : Hidebinding/Tethering skin score of Furst et al , Rodnan skin score, Kahaleh skin score

g. Hirsutism : Ferriman \& gallwey score

h. Pemphigus vulgaris : PAAS ,ABSIS , PDAI

i. Melasma : MASI

j. Acne : shelley kligman, james tisserland, michealson, cooks grading

k. Urticaria : UAS

1. Alopecia areata : SALT score

m. Dyshidrotic eczema : DASI

n. Onychomycosis : OSI

o. Lupus erythematosus : CLASI

p. Sarcoidosis : CSAMI

1 Atopic Dermatitis :

III. Review

It is a chronic condition and is one of the four most common chronic inflammatory skin disorders. Measuring the severity of $\mathrm{AD}$ as objectively as possible is extremely important in clinical practice and for research purposes. The criteria of Hanifin and Rajka are regarded as classic, but are subject to criticism because of their complexity and unpractical aspects ${ }^{2}$

Scores that are commonly used for objective assessment of atopic dermatitis are

1. SCORing Atopic Dermatitis (SCORAD)

DOI: 10.9790/0853-150798999

www.iosrjournals.org

$89 \mid$ Page 
2. The Six Area, Six Sign Atopic Dermatitis (SASSAD) severity score

\subsection{Scorad (Scoring Atopic Dermatitis) :}

Developed by the European Task Force on atopic dermatitis in 1993, it is the most commonly used scoring system for measuring the severity of atopic dermatitis. It is used to standardize the assessment of atopic dermatitis and to help in the interpretation of therapeutic studies.

The disadvantage of this scoring system is the significant interobserver variation which makes subsequent assessment of the patient by the same observer necessary

The Scorad Index is a composite score based on 3 subscores:

\begin{tabular}{|l|l|}
\hline A & The extent score based on body surface area calculated using the 'Rule of 9'. \\
\hline B & $\begin{array}{l}\text { Intensity score based on } 6 \text { clinical findings in atopic dermatitis, namely erythema, } \\
\text { edema or papulations, oozing or crusting, excoriation, lichenification, dryness, graded } \\
\text { on a scale of } 0-3(0-\text { absent, } 1 \text { - mild, 2- moderate, 3- severe). }\end{array}$ \\
\hline C & $\begin{array}{l}\text { The score for pruritus and sleep loss graded on a visual analog scale of } 0 \text { to 10. The } \\
\text { severity is based on the average extent for the last 3 days or nights. }\end{array}$ \\
\hline
\end{tabular}

Final formula for calculation of SCORAD is as follows: SCORAD $=\mathrm{A} / 5+7(\mathrm{~B} / 2)+\mathrm{C}$.

\subsection{Sassad :}

The Six Area, Six Sign Atopic Dermatitis severity score has proved to be a simple and effective system for recording and monitoring disease activity in atopic dermatitis. The score is obtained by grading six signs-

1) erythema,

2) exudation,

3) excoriation,

4) dryness,

5) cracking and

6) lichenification,

Each on a scale of 0 (absent), 1 (mild), 2 (moderate), or 3 (severe), at each of six sites (arms, hands, legs, feet, head and neck, trunk).

The maximum score is 108.

\subsection{Other Scores For Atopic Dermatitis}

\begin{tabular}{|l|l|}
\hline $\begin{array}{l}\text { ADASI (Atopic dermatitis area severity } \\
\text { index score) }\end{array}$ & $\begin{array}{l}\text { Uses a three color-coding system of body charts and counting grid to measure } \\
\text { the number of points falling on the different areas . }\end{array}$ \\
\hline $\begin{array}{l}\text { The Leicester score for atopic dermatitis } \\
\text { disease }\end{array}$ & $\begin{array}{l}\text { Forerunner to the SASSAD . Involves assessing 10-body zones for erythema, } \\
\text { activity excoriation, dryness, cracking, and lichenification, giving a maximum } \\
\text { score of } 150\end{array}$ \\
\hline $\begin{array}{l}\text { Grading score of Rajka and Langeland } \\
\text { for severity }\end{array}$ & Most suitable for baseline assessment rather than for monitoring severity \\
\hline $\begin{array}{l}\text { Simple scoring system for atopic dermatitis } \\
\text { of COSTA }\end{array}$ & $\begin{array}{l}\text { Scores 10 severity criteria (0-7) and 10 topographic sites (0-3) giving a } \\
\text { maximum OF 100. }\end{array}$ \\
\hline Basic clinical scoring system (BCSS) & $\begin{array}{l}\text { Simple score that assesses the presence or absence of disease in 5 body sites, } \\
\text { giving a total score of 5. }\end{array}$ \\
\hline Atopic dermatitis severity index (ADSI) & $\begin{array}{l}\text { Assessment of erythema, pruritus, exudation, excoriation, and lichenification, } \\
\text { each on a scale of 0 to 3 to give a maximum score of 15 }\end{array}$ \\
\hline $\begin{array}{l}\text { Assessment measure for atopic dermatitis } \\
\text { (ADAM) }\end{array}$ & $\begin{array}{l}\text { Most recently developed. Assessment of 6 body areas for scale and/or dryness, } \\
\text { lichenification, erythema, and excoriations (0-3), and 4 further body areas for } \\
\text { the presence or absence of eczema }\end{array}$ \\
\hline Eczema area severity index (EASI) & $\begin{array}{l}\text { Composite index that includes an assessment of erythema, infiltration and/or } \\
\text { papulation, excoriation and lichenification, each on a scale of 0-3 }\end{array}$ \\
\hline
\end{tabular}

\section{Psoriasis :}

Psoriasis is a chronic inflammatory papulosquamous disorder characterized by erythematous plaques with superimposed silvery white adherent scales .

PASI score is currently the gold standard score for the assessment of extensive psoriasis, but has the limitation of interobserver variation.

Four sites of affection, the head (h), upper limb (u), trunk (t) and lower limbs (l), are separately scored.

1. Three parameters erythema, induration and desquamation, each of which is graded on a severity scale of 0 to 4 , where 
- $0=$ nil,

- 1 = mild,

- 2 = moderate,

- 3 = severe and

- 4 = very severe.

2. The area wise percentage involvement of the involved sites is calculated as:

- $1=$ less than $10 \%$ area;

- $2=10-29 \%$

- $3=30-49 \%$

- $4=50-69 \%$;

- $5=70-89 \%$; and

- $6=$ more than $90 \%$.

The final formula for PASI score is:

PASI = 0.1 (Eh + Ih + Dh) Ah + 0.2 (Eu + Iu + Du $) \mathrm{Au}+0.3(\mathrm{Et}+\mathrm{It}+\mathrm{Dt}) \mathrm{At}+0.4(\mathrm{El}+\mathrm{Il}+\mathrm{Dl}) \mathrm{Al}$ The maximum score of PASI is $72 .^{3}$

Other Scores Used For Psoriasis

\begin{tabular}{|l|l|}
\hline $\begin{array}{l}\text { Evaluation for prognosis with averaged } \\
\text { PASI (E-PAP) }\end{array}$ & $\begin{array}{l}\text { New method for evaluating clinical symptoms of } \\
\text { psoriasis during the observation period, by } \\
\text { adding a parameter of time (the number of days } \\
\text { of a disease) to PASI }\end{array}$ \\
\hline Salford psoriasis index (SPI) & $\begin{array}{l}\text { Measures the current extent, psychosocial } \\
\text { disability and past severity of the disease }\end{array}$ \\
\hline $\begin{array}{l}\text { Self administered psoriasis area and } \\
\text { severity index (SAPASI) }\end{array}$ & $\begin{array}{l}\text { Consists of a silhouette of a body for patients to } \\
\text { shade in affected areas and of three modified } \\
\text { visual analog scales for recording the redness, } \\
\text { thickness, and scaliness of an average lesion }\end{array}$ \\
\hline
\end{tabular}

3. Nail Psoriasis :

Scoring system for measuring nail psoriasis is "NAPSI"

Nail plate is divided into quadrants by imaginary longitudinal and horizontal lines

\begin{tabular}{|l|l|}
\hline Nail plate changes & Nail bed changes \\
\hline nail pitting, & onycholysis, \\
\hline leukonychia, & oil drop (salmon patch) \\
\hline red spots in the lunula, & dyschromia, \\
\hline crumbling & splinter hemorrhages \\
\hline & hyperkeratosis \\
\hline
\end{tabular}

score is

0 if the findings are not present,

- 1 if they are present in 1 quadrant of the nail,

- 2 if present in 2 quadrants of a nail,

- 3 if present in 3 quadrants of a nail, and

- 4 if present in 4 quadrants of a nail

Thus each nail has a matrix score (0-4) and a nail bed score (0-4), and the total nail score is the sum of those 2 individual scores (0-8). Sum of the total score of all involved fingernails is the total NAPSI score for that patient at that time

A modified version (mNAPSI) was developed to enhance the face validity and feasibility of this tool a more sensitive scale is needed here in the nail can be given a separate score for all 8 features in each quadrant. The resulting is a 0 to 32 scale ${ }^{2}$ 


\section{Toxic Epidermal Necrosis (Ten)}

Stevens-Johnson syndrome is an immune-complex-mediated hypersensitivity complex that typically involves the skin and the mucous membranes. The score commonly used for assessing the patients of TEN is SCORTEN. Scoring is based on the evaluation of seven independent risk factors within the first 24 hours of admission and on day 3

$30 \%$

\begin{tabular}{ll}
\hline Variable & Value \\
\hline Age & $\geq 40$ year \\
Concurrent illness (malignancy) & Present \\
Heart rate & $\geq 120$ per minute \\
Body surface area involved at day 1 & $\geq 10 \%$ \\
Serum blood urea nitrogen & $>28 \mathrm{mg} / \mathrm{dl}(>10 \mathrm{mmol} / \mathrm{L})$ \\
Serum bicarbonate & $<20 \mathrm{mEq} / \mathrm{L}(<20 \mathrm{mmol} / \mathrm{L})$ \\
Serum glucose & $>252 \mathrm{mg} / \mathrm{dl}(>14 \mathrm{mmol} / \mathrm{L})$ \\
\hline
\end{tabular}

The value of the total number of points determines the predicted mortality:

\begin{tabular}{|l|l|}
\hline POINTS & MORTALITY \\
\hline $0-1$ & $3.2 \%$ \\
\hline 2 & $12.1 \%$ \\
\hline 3 & $35.3 \%$ \\
\hline 4 & $58.3 \%$ \\
\hline$>=5$ & $90 \%$ \\
\hline
\end{tabular}

\section{Vitiligo :}

Vitiligo is an acquired depigmenting disorder of the skin, in which pigment cells (melanocytes) are lost. It presents with well-defined milky-white patches of skin. Vitiligo can be cosmetically very disabling, particularly in people with dark skin.

Two scores designed for the assessment of vitiligo are

vitiligo area severity index (VASI)

vitiligo disease activity score (VIDA).

\subsection{Vitiligo area severity index :}

The percentage of vitiligo involvement is calculated in terms of hand units. One hand unit (which encompasses the palm plus the volar surface of all digits) is approximately equivalent to $1 \%$ of the total body surface area.

The degree of pigmentation is estimated to the nearest of one of the following percentages:

\begin{tabular}{|l|l|}
\hline $100 \%$ & complete depigmentation, no pigment is present \\
\hline $90 \%$ & specks of pigment present \\
\hline $75 \%$ & depigmented area exceeds the pigmented area \\
\hline $50 \%$ & pigmented and depigmented areas are equal \\
\hline $25 \%$ & pigmented area exceeds depigmented area \\
\hline $10 \%$ & only specks of depigmentation present \\
\hline
\end{tabular}

The VASI for each body region is determined by the product of the area of vitiligo in hand units and the extent of depigmentation within each hand unit measured patch.

- Total body VASI $=\square$ All body sites [Hand Units] $\times$ [Residual depigmentation] Vitiligo disease activity score (VIDA) : 
The VIDA is a six-point scale for assessing vitiligo activity. Scoring is based on the individual's own opinion of the present disease activity over time. Active vitiligo involves either expansion of existing lesions or appearance of new lesions.

Grading is as follows: VIDA Score

\section{Scleroderma :}

\begin{tabular}{|l|l|}
\hline+4 & Activity of 6 weeks or less duration \\
\hline+3 & Activity of 6 weeks to 3 months \\
\hline+2 & Activity of $3-6$ months \\
\hline+1 & Activity of $6-12$ months \\
\hline 0 & Stable for 1 year or more \\
\hline-1 & Stable with spontaneous repigmentation since 1 year or more \\
\hline
\end{tabular}

A low VIDA score indicates less activity ${ }^{3}$

The term scleroderma is derived from the Greek words skleros (hard or indurated) and derma (skin) and it is used to describe a disease characterized by progressive skin hardening and induration. Scoring systems used for scleroderma are :

\subsection{Hidebinding/Tethering skin score of Furst et al :}

Sites examined include the face, back, chest, abdomen, arms, forearms, hands, thighs, legs, and feet. The grading of tethering is:

- 0 - skin not tethered or bound down;

- 1 - mild tethering;

- 2 - moderate tethering; and

- 3 - severe tethering.

- The skin score is the total of all points for all sites.

The maximum score is $30 .^{2}$

\section{Other scores for scleroderma :}

\begin{tabular}{|l|l|}
\hline Rodnan skin score in scleroderma & $\begin{array}{l}\text { Examination of 26 sites and grading on a scale of 0 to 4. Involved } \\
\text { maximum score is 104. Too extensive and tedious. }\end{array}$ \\
\hline $\begin{array}{l}\text { Modified Rodnan skin score in scleroderma using 17 } \\
\text { SITES }\end{array}$ & $\begin{array}{l}\text { Involves evaluation of fewer sites (17 rather than 26) and fewer grades (0 } \\
\text { to 3) }\end{array}$ \\
\hline $\begin{array}{l}\text { Modified Rodnan skin score in scleroderma using 5 } \\
\text { SITES }\end{array}$ & Simple score of 5 sites and grading of 0 to 2. Maximum score is 10. \\
\hline Kahaleh skin score in scleroderma & Measures skin thickening at 22 sites and a grading of 0 to 3. \\
\hline
\end{tabular}

\section{Hirsutism :}

Hirsutism is the excessive hairiness on women in those parts of the body where terminal hair normally is absent or minimal, such as a beard or chest hair. It refers to a male pattern of body hair (androgenic hair) and it is therefore primarily of cosmetic and psychological concern.

The Ferriman and Gallwey score measures hirsutism in women by the degree of hair growth in 11 body regions, out of which the forearm and hand, lower leg and feet are not included in the "hormonal" score. This is a time consuming and apparently complex semiquantitative scoring system for hirsutism.

FG used a scoring system loosely based on evaluating 11 body areas, including the

- upper lip,

- chin, chest,

- upper back,

- lower back,

- upper arm,

- arm,

- $\quad$ upper and lower abdomen,

- thighs and legs.

Terminal hair hairs can be distinguished clinically from vellus hairs primarily by their length (i.e. $>0.5 \mathrm{~cm}$ ), coarseness, and pigmentation. In contrast, vellus hairs generally measure $<0.5 \mathrm{~cm}$ in length, are soft and nonpigmented.

A score of 0-4 was assigned to each area examined, based on the visual density of terminal hairs,

- 0 represented the absence of terminal hairs, 
- a score of 1 minimally evident terminal hair growth, and

- a score of 4 extensive terminal hair growth.

Even if hirsutism is present bilaterally on the extremities (upper arms, forearms, thighs and lower legs), only a single value is entered.

Ferriman Gallwey hormonal hair score $=$ Sum of all scores.

The minimum score is zero and the maximum is 36 .

Obviously, the higher the score, the more hirsute is the woman.

- A score of less than 8 is considered as non hirsute,

- 8-16 as mild hirsutism,

- 17-25 as moderate hirsutism, and

- more than 25 as severe hirsutism.

A score of more than 6 in Caucasian women indicates abnormal hair distribution. Each ethnic group may have a different upper limit of the normal value. ${ }^{2}$

8. Pemphigus Vulgaris : Pemphigus is an autoimmune blistering disorder characterized by bulloous lesion present through the body and oral mucosa which rupture on trauma or spontaneously to form eroded areas.

Pemphigus area and activity score (PAAS): is a specific scoring system that has been suggested by Agarwal et al for the clinical assessment of severity and progression of pemphigus vulgaris. PAAS is calculated separately for cutaneous and mucous membrane lesions

\begin{tabular}{|c|c|c|c|c|c|c|c|}
\hline \multirow{2}{*}{ Clinical markess } & \multicolumn{7}{|c|}{ Cinical scous } \\
\hline & $\overline{0}$ & 1 & 2 & 3 & 4 & 5 & B \\
\hline \multicolumn{8}{|l|}{ A: Activity } \\
\hline a. No. of new bistersiday & 0 & 1.5 & 6.10 & 11.20 & $\$ 20$ & , & . \\
\hline b. Perigheral extension of exising bisters & N & Mit & Moderale & Extensive & . & . & - \\
\hline c. Nikolsky's sign & Negative & Pentetions & Distant & . & , & , & . \\
\hline B; Ava $(\%)$ & $\mathrm{N}^{\circ}$ & 0.15 & 16.30 & 31,50 & 51.70 & 71,90 & 890 \\
\hline
\end{tabular}

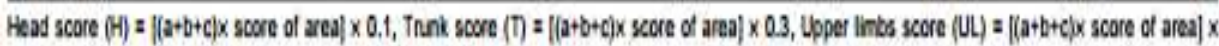
02, Lower Imbs score $(\mathrm{L})=(\| \mathrm{a}+\mathrm{b}+\mathrm{C}) \times$ scoue of arcal $\times 0.4$, Tolal cutaneous score $\mathrm{H}+\mathrm{T}+\mathrm{UL}+\mathrm{LL}$

on mucous mombranas

\begin{tabular}{lllll}
\hline \multicolumn{5}{c}{ Cfrical scoses } \\
\hline Markers & 0 & 1 & 2 & 3 \\
\hline Area & Ni & 1 sile & 2 sites & $>2$ siles \\
Severity & Na & Mid & Moderate & Severe \\
\hline Mucous mernbrane soore $(M M)$ & $=$ Area sooce + Severity score
\end{tabular}

Autoimmune Bullous Skin Disorder Intensity Score(ABSIS):

Cutaneous involvement score consists of 2 parts: percentage of involvement (body surface area [BSA]) and the quality of lesions. The quality of lesions is assessed by multiplying the extent of BSA by a weighting factor.

- Erosive, exudative lesions, and positive Nikolsky's sign obtain a weighting factor of 1.5;

- erosive, dry lesions have a weighting factor of 1.0; and

- reepitheliazed lesions (excluding postinflammatory erythema and/or hyperpigmentation) have a weighting factor of 0.5 .

Oral involvement is based on 2 scores 1)comprising the extent (presence of lesions) and 2) severity (discomfort during eating and drinking) of the disease. The extent is given a score of 0 or 1 (absence or presence, respectively) for 11 different parts of the mouth.These 11 sites are upper and lower gingival mucosae, upper and 
lower lip mucosae, left and right buccal mucosae, the tongue, floor of the mouth, hard and soft palate, and the pharynx. The factor discomfort is attributed a score of $0,0.5$, or 1 for the symptoms of never experiencing problems, pain/bleeding occurring sometimes, or pain/bleeding occurring always, respectively.

The maximum scores for oral involvement are 11 for extent and 45 for severity.

Pemphigus Disease Area Index (PDAI) :

It has 3 components relating to the skin, scalp, and mucous membranes. The skin has activity and damage scores.The total maximum score is 263 , consisting of 250 points from the activity and 13 from damage scores. ${ }^{4}$

\section{Melasma :}

Melasma is a chronic skin disorder that results in symmetrical, blotchy, brownish facial pigmentation. It can lead to considerable embarrassment and distress.

This form of facial pigmentation is sometimes called chloasma, but as this means green skin, the term melasma (brown skin) is preferred.

Melasma area severity index (MASI) is developed by Kimbrough-Green et al for the assessment of melasma.The severity of the melasma in each of the four regions (forehead, right malar region, left malar region and chin) is assessed based on three variables:

- $\quad$ percentage of the total area involved (A),

- darkness (D), and

- homogeneity (H).

\begin{tabular}{|c|c|c|}
\hline AREA & DARKNESS & HOMOGENEITY \\
\hline $0=$ no involvement & $\begin{array}{l}0=\text { normal skin color without } \\
\text { evidence } \\
\text { hyperpigmentation }\end{array}$ & $\begin{array}{l}0=\text { normal skin color without } \\
\text { evidence of hyperpigmentation; }\end{array}$ \\
\hline $1=<10 \%$ & $\begin{array}{ll}\begin{array}{l}1=\text { barely } \\
\text { hyperpigmentation }\end{array} & \text { visible } \\
\end{array}$ & $1=$ specks of involvement; \\
\hline $2=10-29 \%$ & $2=$ mild hyperpigmentation & $2=$ small patchy areas of $<1.5 \mathrm{~cm}$ \\
\hline $3=30-49 \%$ & $\begin{array}{l}3=\text { moderate } \\
\text { hyperpigmentation }\end{array}$ & $\begin{array}{l}3=\text { patches of involvement }>2 \mathrm{~cm} \\
\text { diameter }\end{array}$ \\
\hline $4=50-69 \%$ & $4=$ severe & $\begin{array}{l}\text { 4=uniform skin involvement } \\
\text { without any clear areas }\end{array}$ \\
\hline \multicolumn{3}{|l|}{$5=70-89 \%$} \\
\hline $6=90-100 \%$ & & \\
\hline
\end{tabular}

To calculate the MASI score, the sum of the severity grade for darkness (D) and homogeneity (H) is multiplied by the numerical value of the areas (A) involved and by the percentages of the four facial areas (10-30\%). Total MASI score: Forehead $0.3(\mathrm{D}+\mathrm{H}) \mathrm{A}+$ right malar $0.3(\mathrm{D}+\mathrm{H}) \mathrm{A}+$ left malar $0.3(\mathrm{D}+\mathrm{H}) \mathrm{A}+$ chin $0.1(\mathrm{D}+\mathrm{H}) \mathrm{A}$. Nowadays modified version is employed where in homogeneity is not considered.$^{5}$

\section{Acne Vulgaris :}

Acne vulgaris is a common chronic skin disease involving blockage and/or inflammation of pilosebaceous units (hair follicles and their accompanying sebaceous gland). Acne can present as noninflammatory lesions, inflammatory lesions, or a mixture of both, affecting mostly the face but also the back and chest.

10.1 In 1956, Pillsbury, Shelley and Kligman published the earliest known grading system. The grading includes the following: ï

Grade 1: Comedones and occasional small cysts confined to the face. ï

- Grade 2: Comedones with occasional pustules and small cysts confined to the face.

- Grade 3: Many comedones and small and large inflammatory papules and pustules, more extensive but confined to the face.

- Grade 4: Many comedones and deep lesions tending to coalesce and canalize, and involving the face and the upper aspects of the trunk.

10.2 In 1958, James and Tisserand in their review of acne therapy, provided an alternative grading scheme

Grade 1: Simple non-inflammatory acne - comedones and a few papules.

- Grade 2: Comedones, papules and a few pustules. ï

- Grade 3: Larger inflammatory papules, pustules and a few cysts; a more severe form involving the face, neck and upper portions of the trunk. $\ddot{i}$ 
- Grade 4: More severe, with cysts becoming confluent.

10.3 Severity index [Michaelsson] : Simple score, by counting the number of open or closed comedones, papules, pustules and infiltrated lesions. Severity index is

0.5 for comedones,

1 for a papule,

- 2 for a pustule,

- 3 for infiltrated lesion and

- 4 for cystic lesions.

Multiplying each type of lesion with its severity index and adding them together calculated the total severity score.

10.4 In 2008, Hayashi et al., [13] used standard photographs and lesion counting to classify acne into four groups. They classified acne based on the number of inflammatory eruptions on half of the face as

0-5, ìmildî;

6-20, ìmoderatê̂;

21-50, ìsevereî; and

more than 50 , ìvery severe. $\hat{1}^{6}$

\section{Urticaria :}

Urticaria, commonly referred to as hives, appears as raised, well-circumscribed areas of erythema and edema involving the dermis and epidermis that are very pruritic (see the image below). It may be acute ( $<6 \mathrm{wk})$ or chronic (>6 wk).

Urticaria activity score (UAS) The UAS consisted of the sum of the wheal number score and the itch severity score.

The wheal numbers are graded from 0 to 3 as follows:

- 0 - less than 10 small wheals (diameter, $<3 \mathrm{~cm}$ );

- 1 - 10 to 50 small wheals or less than 10 large wheals (diameter, $>3 \mathrm{~cm}$ );

- 2 - greater than 50 small wheals or 10 to 50 large wheals; and

- 3 - almost the whole body is covered.

The severity of the itching is graded from 0 to 3 ( 0 , none; 1 , mild; 2 , moderate; and 3 , severe $)^{2}$

\section{Alopecia Areata :}

Alopecia areata, also known as spot baldness, is an autoimmune disease in which hair is lost from some or all areas of the body, usually from the scalp due to the body's failure to recognize its own body cells and subsequent destruction of its own tissue as if it were an invader.

National Alopecia Areata Foundation working committee has devised "Severity of Alopecia Tool score" (SALT score).

Scalp is divided into 4 areas namely,

- Vertex - $40 \%(0.4)$ of scalp surface area;

- $\quad$ right profile of scalp - $18 \%(0.18)$ of scalp surface area;

- left profile of scalp - 18\% (0.18) of scalp surface area;

- Posterior aspect of scalp - 24\% (0.24) of scalp surface area.

Percentage of hair loss in any of these areas is percentage hair loss multiplied by percent surface area of the scalp in that area.

SALT score is the sum of percentage of hair loss in all above mentioned areas. For e.g., if the percentage hair loss in vertex, right profile, left profile and posterior aspect is $20,30,40$ and $50 \%$ respecively; then, SALT score $=(20 \times 0.4)=(30 \times 0.18)+(40 \times 0.18)+(50 \times 0.24)=8+5.4+7.2+12=32.6^{2}$

\section{Dyshidrotic Eczema :}

It is a form of hand eczema which is characterized by a pruritic vesicular eruption on the fingers, palms, and soles. The condition affects teenagers and adults and may be acute, recurrent, or chronic. A more appropriate term for this vesicular eruption is pompholyx, which means bubble

Dyshidrotic eczema area and severity index (DASI) Based on the severity grade of single items - number of vesicles per square centimetre (V), erythema (E), desquamation (S) and itch (I) - and the extension of the affected area $(\mathrm{A})$ and is calculated with defined score points (p) as: 
DASI $=(\mathrm{pV}+\mathrm{pE}=\mathrm{pS}+\mathrm{pI}) \times \mathrm{pA}$

DASI was found to be a simple and useful tool to assess the severity of dyshidrotic eczema and the effect of therapy.

\section{Onychomycosis :}

Onychomycosis is a fungal infection of the toenails or fingernails that may involve any component of the nail unit, including the matrix, bed, or plate. Onychomycosis can cause pain, discomfort, and disfigurement and may produce serious physical and occupational limitations, as well as reducing quality of life.

Onychomycosis Severity Index (OSI) includes

area of involvement,: measured using the boundaries of the lateral nail folds, proximal nail fold, and distal nail groove

- One point is given if the disease involves $1 \%$ to $10 \%$ of the nail,

- 2 points for $11 \%$ to $25 \%$,

- 3 points for $26 \%$ to $50 \%$,

- 4 points for $51 \%$ to $75 \%$, and

- 5 points for $76 \%$ or more of the nail.

Proximity of disease to the matrix, the nail is divided transversely into quarters starting distally and extending proximally. As the leading edge of disease moves proximally, it is given a score of 1 through 4 depending on which quarter the leading edge extends to.

- Occurrence of dermatophytomas, : The presence of a patch or longitudinal streak is graded with 10 points, thereby pushing any nail with a dermatophytoma into the moderate or severe category depending on the area and length of involvement. More than 1 dermatophytoma may exist in the same nail; however, only 1 is graded, for a maximum of 10 points.

Presence of severe subungual hyperkeratosis $(>2 \mathrm{~mm})$ : The presence of subungual hyperkeratosis of greater than $2 \mathrm{~mm}$ is given a score of 10 points. If less than $2 \mathrm{~mm}$ of hyperkeratosis is present, no points are awarded. It is important that only the area of debris and not the nail plate itself is measured when assessing subungual hyperkeratosis.

To assess the nail, the score for the area of involvement (range, 0-5) is multiplied by the score for the proximity of disease to the matrix (range, 1-5), and 10 points are added if a longitudinal streak or a patch (dermatophytoma) is present or if there is greater than $2 \mathrm{~mm}$ of subungual hyperkeratosis. If multiple streaks or both a streak and a patch are present, only 10 points are given. Because a longitudinal streak or a patch and subungual hyperkeratosis represent a high fungal burden, the presence of these features is scored only once. ${ }^{8}$

\section{Clasi (Cutaneous Le Disease Area And Severity Index) :}

Lupus erythematosus (LE) is an autoimmune connective tissue disorder that can affect one or several organs. Circulating autoantibodies and immune complexes are due to loss of normal immune tolerance and are pathogenic. Clinical features of LE are highly variable. LE nearly always affects the skin to some degree.

Cutaneous LE comprises several chronic and relapsing LE-specific and LE-nonspecific inflammatory conditions. There can be some overlap.

- LE-specific has been classified as acute, subacute, intermittent and chronic. Lesions may be localised or generalised. In LE-specific cutaneous LE, lesions are often induced by exposure to sunlight.

- LE-nonspecific cutaneous LE may relate to systemic LE or other autoimmune disease.

For assessment of cutaneous lupus erythematosus, two parameters are used namely : the disease activity(erythema and scaling )and the damage(dyspigmentation and scarring/atrophy/paniculitis) caused by the disease. $^{9}$

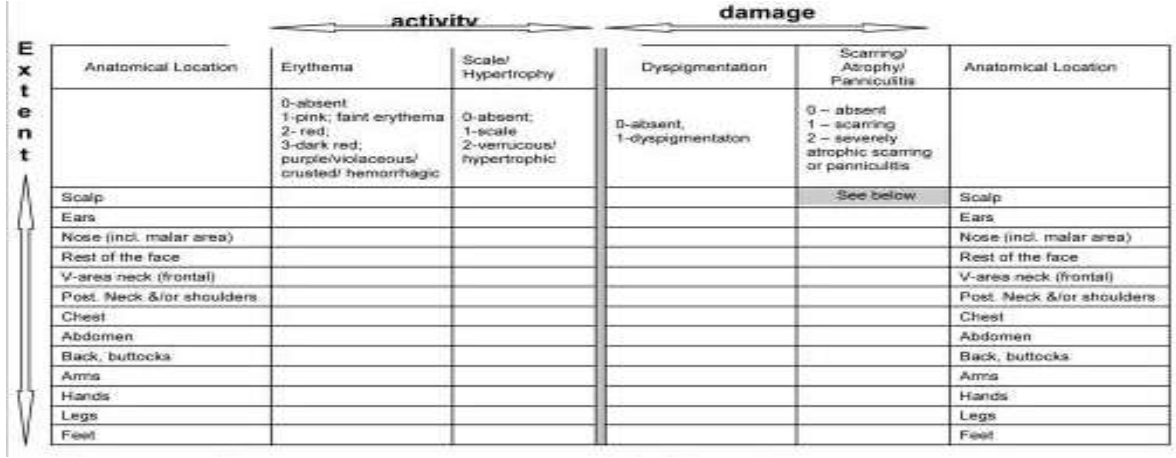




\section{Mucous membrane}

\begin{tabular}{l|l}
\multicolumn{2}{|l}{ Mucous membrane lesions (examine if patient confirms involvement) } \\
$\begin{array}{l}\text { 0-absent; } \\
\text { 1-lesion or ulceration }\end{array}$ & \\
\hline
\end{tabular}

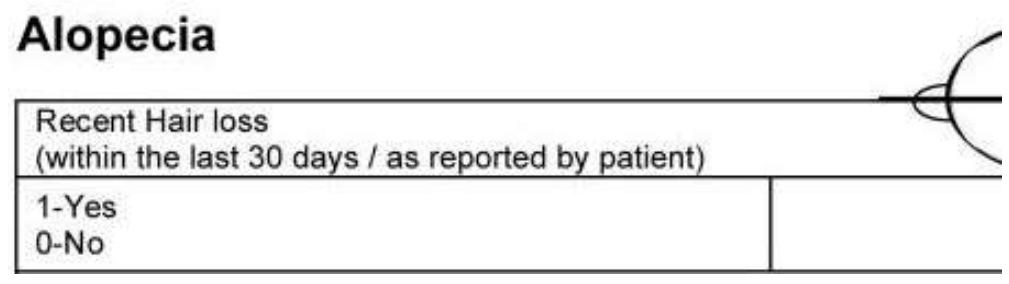

16. Sarcoidosis :

Sarcoidosis is a multisystem inflammatory disease of unknown etiology that manifests as noncaseating granulomas, predominantly in the lungs and intrathoracic lymph nodes.

Dermatologic manifestations may include the following:

- Erythema nodosum

- A lower-extremity panniculitis with painful, erythematous nodules (often with Löfgren syndrome)

- Lupus pernio (the most specific associated cutaneous lesion)

- Violaceous rash on the cheeks or nose (common)

- Maculopapular plaques (uncommon)

\section{Cutaneous Sarcoidosis Activity and Morphology Instrument (CSAMI)}

Clinical signs are documented according to the worst affected lesion within each anatomic area and summed, Maximal score ranges of 0-165 for Activity and 0-22 for Damage. ${ }^{10}$

\begin{tabular}{|c|c|c|c|c|c|c|}
\hline \multicolumn{5}{|c|}{ ACTIVITY } & \multicolumn{2}{|c|}{ Dasmes, } \\
\hline & Inflammation & $\begin{array}{c}\text { induration } \\
\text { of } \\
\text { Depression }\end{array}$ & $\begin{array}{l}\text { Suirface } \\
\text { Change }\end{array}$ & Area & $\begin{array}{l}\text { Post-infammatory } \\
\text { rescuit }\end{array}$ & \\
\hline $\begin{array}{l}\text { Anatomical } \\
\text { Lecation }\end{array}$ & 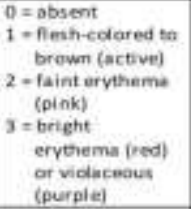 & $\begin{array}{l}0=\text { flat } \\
1=<1 \mathrm{~mm} \\
2=1-2 \mathrm{~mm} \\
3=>2 \mathrm{~mm}\end{array}$ & 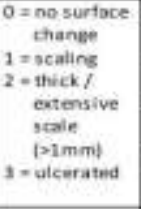 & $\begin{array}{c}1=\text { sinde } \\
\quad \begin{array}{l}\text { lenion } \\
2\end{array} 2<25 \% \\
\text { of site } \\
4=25-50 \% \\
\text { of site } \\
5=>50 \% \\
\text { of site }\end{array}$ & $\begin{array}{l}0=\text { no residual } \\
1 \text { - hppe- - hypo- } \\
\text { pigmentation } \\
2 \text { - starting }\end{array}$ & $\begin{array}{l}\text { Anatomical } \\
\text { Locatien }\end{array}$ \\
\hline Scaip & & & & & & Seaip \\
\hline $\operatorname{Tan}$ & & & & & & Ean: \\
\hline $\begin{array}{l}\text { Periorifidal } \\
\text { (eyes, meuth) }\end{array}$ & & & & & & $\begin{array}{l}\text { Perionticist } \\
\text { (eves, mouth) }\end{array}$ \\
\hline $\begin{array}{l}\text { Nose } \\
\text { (induding } \\
\text { narse) }\end{array}$ & & & & & & $\begin{array}{l}\text { Noses } \\
\text { findusing } \\
\text { nares) }\end{array}$ \\
\hline Aest of face & & & & & & Aest of face \\
\hline Neck & & & & & & Nexk \\
\hline Chest & & & & & & Chest \\
\hline Adbomen & & & & & & Abdomen \\
\hline $\begin{array}{l}\text { Back find: } \\
\text { buttocks? }\end{array}$ & & & & & & $\begin{array}{l}\text { Back jed. } \\
\text { buttocks? }\end{array}$ \\
\hline $\begin{array}{l}\text { Arms bines. } \\
\text { hands) }\end{array}$ & & & & & & $\begin{array}{l}\text { Arms (ind. } \\
\text { hands) }\end{array}$ \\
\hline $\begin{array}{l}\text { Legs lind. } \\
\text { feet) }\end{array}$ & & & & & & $\begin{array}{l}\text { Legs lind. } \\
\text { feet? }\end{array}$ \\
\hline
\end{tabular}

\section{Conclusion}

To conclude the above review, provides an insight into the various scoring systems used in dermatology in detail .These scoring systems are used for predicting the prognosis of the disease . 


\section{References}

[1]. DS Krupashanker, Scoring Systems in Dermatology (Manipal, India, 2009)

[2]. Bhor U, et al., Scoring systems in dermatology, Indian journal of dermatology, leprology and venerology, Year 2006, Volume 72, Issue 4 [p. 315-321]

[3]. Amir Feily , Vitiligo Extent Tensity Index (VETI) score: a new definition, assessment and treatment evaluation criteria in vitiligo , dermatology practicle and conceptual, oct 2014 (p. 81-84)

[4]. Sanjiv grower, Scoring system in pemphigus, Indian journal of dermatology, mar-apr 2011 56(2) (145-149)

[5]. Imran Majid, Inaamul Haq, [...], and Tasleem Arif , Proposing Melasma Severity Index: A New, More Practical, Office-based Scoring System for Assessing the Severity of Melasma , Indian journal of dermatology , jan-feb 2016 69(1) (39-44)

[6]. Balaji Adityan, Rashmi Kumari, Devinder Mohan Thappa alaji Adityan, Rashmi Kumari, Devinder Mohan Thappa, Scoring systems in dermatology, Indian J Dermatol Venereol Leprol | May-June 2009 | Vol 75 | Issue 3

[7]. E. Held, R. Skoet, J.D. Johansen and T. Agner, The hand eczema severity index (HECSI): a scoring system for clinical assessment of hand eczema. A study of inter- and intraobserver reliability, british journal of dermatology, feb 2005 , issue 52 (302-307)

[8]. Caitlin Carney, MD; Antonella Tosti, MD; Ralph Daniel, MD , JAMA Dermatology , New Classification System for Grading the Severity of Onychomycosis, nov 2011 , vol147 (11)

[9]. Joerg Albrecht, Lynne Taylor, [...], and Victoria P. Werth, The CLASI (Cutaneous LE Disease Area and Severity Index): an outcome instrument for cutaneous lupus erythematosus , journal of investigative dermatology , nov 2005 , 885-894

[10]. Misha Rosenbach, MD, Howa Yeung, BS, [...], and Joel M. Gelfand, MD, Reliability and Convergent Validity of the Cutaneous Sarcoidosis Activity and Morphology Instrument for Assessing Cutaneous Sarcoidosis , JAMA Dermatology , may 2013 , 149(5) , 10.1001 